\title{
Evolução de caverna em quartzito e processos cársticos em São Thomé das Letras-MG: contribuição ao estudo de sistemas cársticos em rochas silicáticas
}

\author{
Roberto Marques Neto*
}

\section{Resumo}

O objetivo deste artigo é mostrar a natureza dos processos cársticos em São Thomé das Letras-MG e propor um modelo de evolução para a Gruta do Sobradinho, bastante representativa da dinâmica cárstica na área.

Palavras-chave: Geomorfologia cárstica, quaternário, dissolução, neotectônica.

Evolution of cavern in quartzite and karstic process in São Thomé das Letras-MG: contribuition at the study of the karstic systems in silicatic rocks

\begin{abstract}
This article aims to shows the nature of karstic process in São Thomé das Letras-MG and propose a model of evolution to the Gruta do Sobradinho, enough representative of the karstic dynamics in the area.

Key words: Karstic geomorphology, quaternary, dissolution, neotectonic.

* Mestrando do PPGG da UNESP - Rio Claro, bolsista CNPQ (betogeografia@ig.com.br).
\end{abstract}

Geosul, Florianópolis, v. 23, n. 45, p 105-121, jan./jun. 2008 
MARQUES NETO, R. Evolução de caverna em quartzito e processos ...

\section{Introdução}

Os relevos cársticos, elaborados em sua maior parte sobre rochas carbonáticas, correspondem a aproximadamente $10 \%$ da superfície da Terra, distinguindo-se de outros conjuntos geomorfológicos através de uma coleção de formas típicas da paisagem cárstica, como dolinas, uvalas, poljés, cavernas, abismos, lapiás, sumidouros, vales cegos, torres, entre outras.

É estimado que os calcários, a maior parte deles de origem biológica, formados pela precipitação do carbonato de cálcio, perfaçam uma distribuição espacial entre 20 a 80 milhões de $\mathrm{km}^{2}$ dos 400 milhões de $\mathrm{km}^{2}$ ocupados por rochas sedimentares (LAPORTE, 1969).

$O$ estudo da forma, gênese e dinâmica dos relevos elaborados sobre rochas solúveis em água, sejam elas de origem biogênica ou silicatos como arenitos, quartzitos, granitos e basalto, compõe o objeto de estudo da geomorfologia cárstica (KOHLER, 1995).

O conjunto espacial compreendido por uma paisagem cárstica, para efeito de definição, pode ser compartimentado em um domínio superficial (exocarste), um domínio subsuperficial (epicarste) e um outro subterrâneo (endocarste), cada um deles apresentando estruturas e mecanismos responsáveis pela operação de processos geomorfológicos atuais e, ao mesmo tempo, funcionando como registro de processos ocorridos no passado (PILÓ, 2000).

Toma vulto, dessa maneira, a relevância do estudo das formas e processos cársticos no âmbito do entendimento das oscilações climáticas do Quaternário e dos mecanismos de evolução morfológica que operaram em diferentes contextos paleoclimáticos, bem como em sintonia com o quadro neotectônico intraplaca vigente, atentando para as diferentes fases morfogenéticas envolvidas na história quaternária da paisagem. Não menos, o estudo do carste deve ser realizado em consonância com a exploração antrópica do território em função de fatores de importância indiscutível, como o valor paisagístico, os potenciais 
MARQUES NETO, R. Evolução de caverna em quartzito e processos ...

econômicos e a fragilidade que é intrínseca à maioria desses sistemas.

A presente comunicação constitui um exame dos processos cársticos operantes no município de São Thomé das Letras-MG, na parte meridional do Estado de Minas Gerais, com considerações sobre a evolução de um endocarste em quartzito (Gruta do Sobradinho) situada no extremo NE do território municipal, próximo ao município de Cruzília. A formação de carste em rochas silicáticas ocorre em diversas localidades do domínio tropical atlântico, sendo registrada em municípios próximos a São Thomé das Letras, como Luminárias-MG e Conceição do Rio Verde-MG, e também em outras localidades do sudeste brasileiro, conforme registrado por Silva (2004) na Serra do Ibitipoca-MG e Uagoda et al. (2006) para o médio vale do Rio Preto, nos estados de Minas Gerais e Rio de Janeiro.

\section{Procedimentos adotados}

A primeira etapa da pesquisa se encarregou de identificar diferentes formas marcadas no território de São Thomé das Letras derivadas de processos de dissolução, a fim de estimar a significância desta modalidade de alteração química na dinâmica da paisagem.

Em seguida, as formas identificadas foram analisadas no contexto da evolução morfoclimática e morfotectônica do relevo, organizando sistematicamente os fatores climáticos e tectônicos em sua atuação conjunta no desenvolvimento de processos cársticos para proposição do modelo evolutivo para a Gruta do Sobradinho, eleita em função de seu maior desenvolvimento morfológico, com entradas e saídas bem marcadas, e de sua relevância econômica, dada sua utilização intensiva enquanto atrativo turístico.

Foram feitas medidas com trena de 5 metros em todos os compartimentos da caverna, com o auxílio de lanterna e bússola. Os valores obtidos foram anotados em caderneta de campo para elaboração de croquis, posteriormente plotados em papel vegetal quadriculado $(1 \mathrm{~cm} \mathrm{X} 1 \mathrm{~cm})$ para a confecção do perfil longitudinal 
MARQUES NETO, R. Evolução de caverna em quartzito e processos ...

da caverna, fazendo-se a representação de um perfil retilíneo onde os compartimentos são projetados lateralmente em planos verticais ao longo de seu eixo, e cuja edição final foi feita no programa Auto Cad 2000. Conforme Lino \& Allievi (1980), esse tipo de perfil é restrito à representação de cavernas de desenvolvimento complexo, sem formação de labirintos, mas que, por outro lado, apresenta os condutos em seu real comprimento e inclinação. A exploração da caverna seguiu as orientações de Auler \& Zogbi (2005). O espaço interno da caverna, percorrido da entrada para a saída, foi medido em todos os compartimentos, sendo anotadas a altura, a largura e o comprimento.

A localização da entrada e saída da caverna e o desvio total do conduto foi obtido através de GPS (Global Position System) marca Garmin modelo eTrex Summit.

\section{Caracterização da área}

Localizado no sul de Minas Gerais (Figura 1), dentro do Planalto do Alto Rio Grande em faixa correspondente ao domínio dos dobramentos pré-cambrianos do Sudeste brasileiro, o município de São Thomé das Letras apresenta paisagem geomorfologicamente composta por morrotes e morros cujo arcabouço geológico é formado por um conjunto de paragnaisses finos bandados designados pelo Projeto RADAMBRASIL (BRASIL 1983) de Gnaisse Piedade. Tal padrão geológicogeomorfológico é interrompido pela ocorrência de cristas monoclinais de orientação preferencial NE-SW (serras de São Tomé, Cantagalo e Sobradinho) balizadas pelos quartzitos micáceos proterozóicos da Bacia Andrelândia (PACIULLO et al. 1993).

O relevo monoclinal apresenta topos proeminentes e aguçados orientados para leste e um reverso suavemente inclinado rumo NW, conforme a direção do mergulho geral das camadas metassedimentares, e pode ser relacionado, nas áreas de topo, à Superfície Sul-Americana de King (1956), do Terciário Inferior. O contato litológico com os gnaisses é abrupto, individualizando um 
MARQUES NETO, R. Evolução de caverna em quartzito e processos ...

padrão em morros e morrotes que incide para uma zona de aplanamento mais recente levado a efeito pelo intemperismo mais profundo perpetrado nos gnaisses, e que corresponde à Superfície Velhas, de idade plio-pleistocênica, conforme a designação do autor supracitado.

Nos setores quartzíticos medra um cerrado formado por pequenas árvores, arbustos, tufos de gramíneas e cactáceas adaptadas às falhas e fraturas existentes na estrutura, e com fisionomia condicionada ao ambiente rupestre. A partir do front em direção aos vales pedimentares adjacentes, onde a litologia passa a ser composta por biotita-muscovita-xistos, registra-se o desenvolvimento da mata latifoliada semidecídua, que também aparece na forma de algumas manchas no conjunto de morrotes e morros.

A pedogênese é bastante restrita nas cristas quartzíticas. Aparece o neossolo litólico nas partes baixas da Serra de São Thomé e pelas vertentes orientadas para oeste das serras do Cantagalo e do Sobradinho. Nos terraços confinados entre as faixas quartzíticas aparecem argissolos, sendo que a pedogênese latossólica toma maior vigor nas áreas de relevo ondulado embasados por litologia gnáissica.

O clima vigente na área é o tropical de altitude, e influencia diretamente em aspectos da paisagem. Exerce efeito orográfico no front das serras de São Tomé, do Cantagalo e do Sobradinho, que interceptam em altitudes de destaque em relação ao entorno as massas de ar provenientes do Oceano Atlântico, retendo teores elevados de umidade pela condensação do ar, que favorece a pedogênese e o desenvolvimento da vegetação florestal nas vertentes orientadas para leste. As vertentes orientadas para oeste, menos servidas pela umidade, apresentam solo raso e vegetação aberta. 


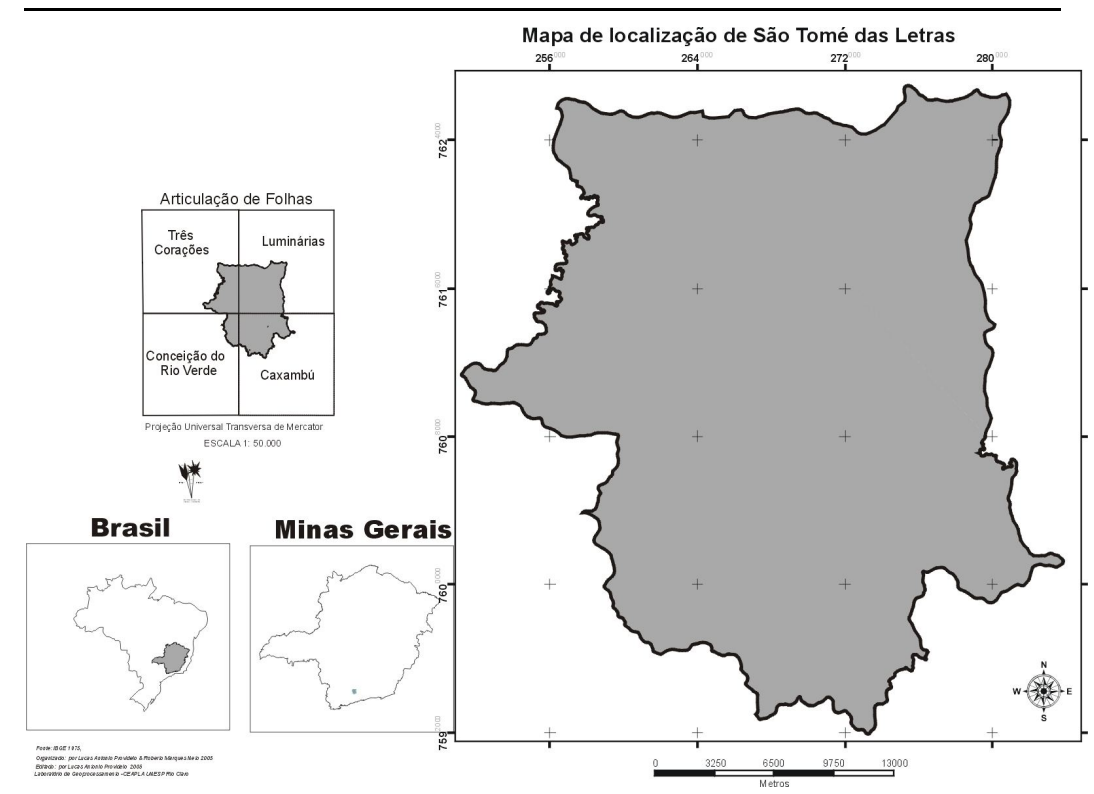

Figura 1. Localização do município de São Thomé das Letras no Estado de Minas Gerais.

\section{Processos cársticos em São Thomé das Letras}

Muitos dos processos cársticos verificados em São Thomé das Letras não são aqui considerados como carste propriamente dito. Pontualmente ocorrem condutos curtos escavados nos planos de fraqueza do quartzito ou depressões fechadas formadas por processos de dissolução, que, embora indique a dinâmica cárstica partilhando da evolução da paisagem no Quaternário, não configuram um sistema cárstico de fato. Com menção a tais processos, consideramos carste, no presente relato, unidades sistêmicas com continuidade espacial e definidas por circulação de matéria e energia, com entradas e saídas bem marcadas e dotadas de uma organização interna que orquestra os processos de dissolução (predominantes), erosão, transporte e deposição, 
MARQUES NETO, R. Evolução de caverna em quartzito e processos ...

responsáveis pela geração de formas cuja evolução pode guardar relações com fatores de ordem climática, tectônica e estrutural.

Os processos pontuais de dissolução aparecem ao longo das faixas quartzíticas em pequenos condutos, depressões fechadas e outras feições de intemperismo cavernoso.

A extração de quartzito no reverso da Serra de São Tomé vem alterando profundamente a paisagem em suas formas e processos. A abertura de crateras e taludes somada às imensas pilhas de estéril modificou severamente a energia do relevo e a natureza dos fluxos de matéria e energia, tendo em vista a contribuição anômala que o sistema recebe expressa pela quantidade enorme de rejeito de mineração. Nas áreas de exploração mineral, portanto, as formas originais do relevo foram substituídas pelo cenário descrito, onde as lavras abertas padronizam a paisagem. A extração conservou, no entanto, encravado numa área de lavra, um bloco quartzítico com altura superior a três metros e um conduto arredondado na parte central, com aproximadamente 1 metro de comprimento e $80 \mathrm{~cm}$ de diâmetro. A origem do conduto advoga em favor de processos de dissolução levados a efeito pela água em zona de fraqueza da rocha.

Estas pequenas formas de dissolução são contumazes nas rochas quartzíticas, e aparecem por toda a região.

Algumas depressões fechadas em franca evolução por dissolução ocorrem na Serra do Sobradinho, setor NE do município, próximas à gruta homônima. Tais feições também estão condicionadas à presença de zonas de fraqueza, perseguindo o mergulho das camadas sedimentares de origem, cuja estratificação plano-paralela facilita a instalação de tal processo. A microtopografia favorece, nos períodos chuvosos, o acúmulo de água, o que é fundamental para ocorrer dissolução.

É muito plausível que as depressões fechadas em discussão, além de um componente climático de evolução congregado a um fator estrutural, também apresente influência de ordem tectônica em seu desenvolvimento, tendo em vista o vigor dos efeitos 
MARQUES NETO, R. Evolução de caverna em quartzito e processos ...

neotectônicos em diversos contextos geológico-geomorfológicos do Sul de Minas. A formação e evolução de tais depressões parece se relacionar também com processos de reativação de cabeceiras, evoluindo regressivamente por dissolução em função do rebaixamento do nível de base decorrente do soerguimento reconhecido para a área, que desencadeia a incisão em clima úmido e provoca reorganização erosiva do sistema. A partir do novo nível de base local, a encosta evolui em sentido remontante, pontuada por processos de dissolução compartilhando da evolução da paisagem.

As formas paleocársticas, desprovidas de funcionalidade cárstica e desconectadas da rede de drenagem atual, também fornecem elementos para interpretação dos processos cársticos quaternários na área de estudo.

A Gruta do Carimbado é exemplarmente representativa da ocorrência de paleocarste na área. Trata-se de um conduto alongado que apresenta dois únicos compartimentos: um salão na entrada e um conduto estreito e longilíneo que se lança a níveis subterrâneos, com prolongamento de alguns quilômetros, extensão esta que não foi estimada na presente pesquisa em função da dificuldade de acesso. Em campo, foram percorridos aproximadamente 200 metros do conduto, bastante estreito, caráter este que se acentua com o aumento da profundidade, até se tornar delgado a ponto de inviabilizar o acesso.

O salão possui altura da ordem de 2,70 metros, largura de 5,60 metros e comprimento de 4,0 metros, da abertura até a configuração do conduto.

A dinâmica cárstica da Gruta do Carimbado não é atuante em tempos hodiernos. A paleodrenagem que engendrou a dissolução é, atualmente, ausente, e o carste, conseqüentemente, sem funcionalidade, uma vez que as águas deixaram de percolar pela zona vadosa para atingirem o nível freático.

De acordo com Bigarella (1994), nas regiões que sofreram dobramento e, conseqüentemente, as rochas se encontram inclinadas, a erosão segue os planos de estratificação, 
MARQUES NETO, R. Evolução de caverna em quartzito e processos ...

preferencialmente ao longo das diáclases presentes na estrutura. A formação do conduto em discussão seguiu esses termos, com a dissolução promovida em zona de fraqueza sobre os níveis argilosos localizados no quartzito, próximo ao contato litológico com os gnaisses, onde foi promovido o alargamento do conduto.

O conduto do Carimbado foi formado, muito provavelmente, sob condições de clima úmido, com água superficial em escoamento concentrado disponível para promover o trabalho de dissolução. À medida que se aprofunda no conduto, o substrato fica mais úmido e lamacento, acusando a maior proximidade com o lençol freático. Tudo indica, portanto, que a água responsável pela dissolução da rocha e formação da gruta se desconectou do sistema hidrográfico para fazer parte do lençol, legando à paisagem um carste abortado e sem funcionalidade.

A abertura da gruta se dá em níveis argilosos, perto da zona de contato entre o quartzito e os paragnaisses, que foram explorados pela paleodrenagem. Tais níveis de alteração estabelecem contato brusco com o quartzito na abertura do conduto, com espessura da ordem de 1,10 metros, aumentando seu desenvolvimento vertical à medida que o conduto se aprofunda, até compor a totalidade da cavidade.

A paleodrenagem que engendrou a formação da gruta provinha de SE, sendo que o paleovale encontra-se entulhado e não está marcado na paisagem atual. No entanto, sua presença pode ser aferida pelo exame dos depósitos coluviais de baixa coesão que preenchem sua antiga zona de passagem. A perda da funcionalidade do carste pode ter se dado na passagem para a última fase semi-árida.

\section{A Gruta do Sobradinho: proposta evolutiva}

A Gruta do Sobradinho constitui uma caverna vadosa com cerca de 130 metros de extensão, localizada na vertente oeste da serra do Sobradinho, tendo evoluído a partir da dissolução imposta ao quartzito. 
MARQUES NETO, R. Evolução de caverna em quartzito e processos ...

O entorno da gruta é caracterizado por vegetação de campo intercalado com pastos plantados que medra sobre solo litólico. Tal fisionomia vegetal avança em direção a cotas mais elevadas até dar lugar a afloramentos arestados do quartzito. $\mathrm{O}$ setor é bastante voltado para a atividade turística, e conta com expressivo fluxo de pessoas, sobretudo nos feriados, e alguns equipamentos elementares, como lanchonetes, restaurantes, aluguel de aparatos para exploração (lanternas) e vendas de artesanato, o que repercute em algumas depredações típicas dessa atividade econômica, notadamente pichações nas paredes e lançamento de lixo pelos visitantes, que freqüentam o local sem nenhuma espécie de restrição e controle, num constrangedor exemplo de exploração turística mal planejada dos ambientes cársticos.

A Gruta do Sobradinho abre-se num salão com teto abobodal cuja entrada possui 9,5 metros de altura e 6,7 metros de largura, dentro do qual pode ser verificado o ponto de ressurgência das águas. Divide-se em seis compartimentos que se intercalam em condutos e pequenos salões, cuja morfometria é mostrada no Quadro 1.

Quadro 1. Medidas dos compartimentos da Gruta do Sobradinho.

\begin{tabular}{|r|r|r|r|}
\hline Compartimento & Altura Média & Largura Média & \multicolumn{1}{c|}{ Comprimento } \\
\hline Compartimento 1 & 9,5 metros & 6,7 metros & 20 metros \\
\hline Compartimento 2 & 3,4 metros & 4,0 metros & 12,8 metros \\
\hline Compartimento 3 & 1,8 metros & 1,5 metros & 22,3 metros \\
\hline Compartimento 4 & 1,85 metros & 1,52 metros & 59,9 metros \\
\hline Compartimento 5 & 1,74 metros & 1,65 metros & 5,0 metros \\
\hline Compartimento 6 & 1,60 metros & 1,85 metros & 10,0 metros \\
\hline
\end{tabular}

Org: MARQUES NETO, R.

As passagens de um compartimento para outro são marcadas por diferenças topográficas, o que permitiu uma aproximação dos desníveis internos em relação ao desnível total medido na entrada e na saída da caverna pelo GPS, onde os satélites podem ser acessados. Embora facilmente verificadas em campo, as mudanças de compartimento são de difícil representação, uma vez que as 
MARQUES NETO, R. Evolução de caverna em quartzito e processos ...

medidas de altura e largura são bastante semelhantes a partir do Compartimento 3, conforme pode ser verificado no perfil longitudinal da caverna (Figura 2).

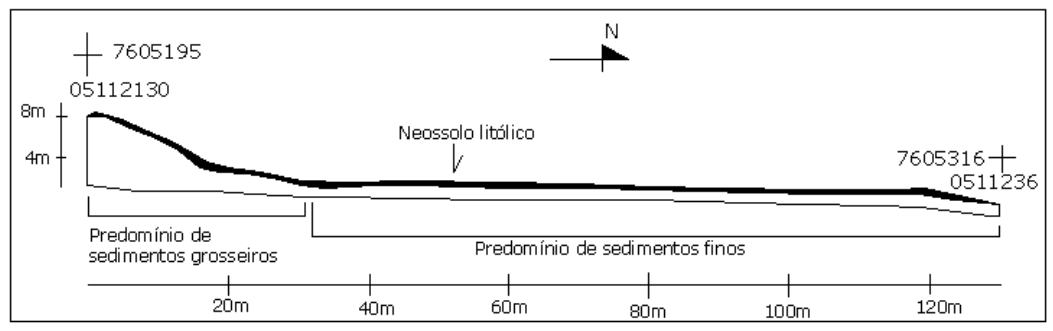

Figura 2. Perfil longitudinal da Gruta do Sobradinho (MARQUES NETO, R.).

As pequenas depressões fechadas que se formam pela dissolução do quartzito que foram anteriormente comentadas aparecem próximas à Gruta do Sobradinho, acusando a dinâmica dissolutiva na vertente oeste da serra homônima.

A Gruta do Sobradinho é formada por um único prolongamento que congrega os inputs e libera os outputs para fora do domínio cárstico. É prudente, entretanto, registrar a possibilidade de existência de outros subsistemas em funcionamento confinados nos poros da estrutura litológica em conexão com o sistema principal atualmente visível, se comportando, pela impossibilidade de acesso, como caixas-pretas. Tais subsistemas, se existirem, podem, por sua vez, além de guardar importantes informações para o entendimento da complexidade intrínseca à gênese e evolução do carste em questão, se desdobrarem em outros subsistemas passíveis de serem reduzidos até a molécula d'água, viabilizando que o tema seja tratado nos termos da geometria fractal. 
MARQUES NETO, R. Evolução de caverna em quartzito e processos ...

O assoalho da Gruta do Sobradinho é preenchido por sedimentos clásticos de variada ordem granulométrica, de grandes blocos a grãos de areia, que se referem, em certa medida, a materiais alóctones derivados da própria evolução in loco da caverna e, em parte, a sedimentos transportados. A maior parte da carga sedimentar está localizada no salão de entrada e no primeiro conduto, diminuindo de tamanho até a saída da cavidade.

A gênese da Gruta do Sobradinho está fortemente ligada ao escoamento e infiltração das águas ao longo dos planos de diaclasamento, seguida da dissolução e remoção do material. Nos moldes do raciocínio exposto por Wernick et al. (1973), a partir de um alargamento inicial, a evolução da caverna se dá por meio de abatimentos seguidos da retirada do material que foi desprendido do ambiente cavernícola.

Em certa medida, a Gruta do Sobradinho pode ter sido formada, da maneira que as depressões de dissolução que a circundam, por efeito de perturbações tectônicas, o que é corroborado pelo fato da área em que se encontra estar sendo submetida a soerguimento litosférico. Da mesma maneira, as formas isoladas apontadas, traduzidas por pequenas depressões fechadas, algumas relativamente alargadas e outras bastante estreitas, tem seu desenvolvimento ligado a movimentos epirogenéticos que serviram como catalisadores do processo de incisão das águas por conta do rebaixamento do nível de base local, colocando em destaque mecanismos endógenos e exógenos de evolução do relevo cárstico na área de estudo. Além disso, o deslocamento de blocos nas zonas de fraqueza favorece a instalação da drenagem na depressão e o conseqüente trabalho de dissolução levado a efeito pela água.

A tectônica exerce, portanto, influência de monta na evolução do relevo cárstico em questão em função do gradiente imposto, que segue o mergulho das camadas e condiciona o sistema hidrológico. Willems et al. (1996) reconhecem a importância do fraturamento e do padrão de estratificação no desenvolvimento de cavidades em rochas não-carbonáticas. 
MARQUES NETO, R. Evolução de caverna em quartzito e processos ...

Conjugado a isso, os efeitos ligados ao clima, bem como as mudanças climáticas ocorridas ao longo do Quaternário, também influenciam os processos de carstificação.

Algumas fases de evolução, que seguem enumeradas, foram levantadas para a Gruta do Sobradinho, com base na sobreposição de agentes climáticos e tectônicos atuando na geomorfogênese.

1. Alteração da fratura - Etapa inicial para o desenvolvimento da caverna, processada em condições climáticas úmidas, com regime de precipitação eficiente para o fornecimento suficiente de água a ser concentrada e assim viabilizar a dissolução do quartzito.

2. Abertura da fenda - A água envolvida no processo, ao atingir o nível de base local, passa a exercer erosão lateral, alargando o conduto e preenchendo a cavidade.

3. Desgaste mecânico - A mudança para um clima mais seco reorientou a evolução da caverna, dando margem a abatimentos e deposição de sedimentos clásticos no assoalho da caverna.

4. Desobstrução do conduto - A retomada da umidade possibilitou a remoção do material e novamente reorientou a evolução por efeito predominante da dissolução química; possíveis canais secundários foram abortados e a drenagem se concentrou, por coalescência interna, em um único eixo, acusando uma condição de maturidade para o carste, que é atualmente constatada.

A evolução da gruta em consideração fornece, conforme exposto, indicações da ação de efeitos climáticos e tectônicos agindo concomitantemente durante o Quaternário, adentrando o Holoceno e sendo verificado em tempos presentes.

\section{Considerações finais}

É plausível argumentar, diante do que foi apresentado, que o processo de soerguimento tectônico que é apontado para o setor meridional do Estado de Minas Gerais, submetido a reconhecida reativação neotectônica intrapalaca, conforme mostram os estudos de uma série de autores (ASMUS \& FERRARI, 1978; SAADI et al. 1989; SAADI, 1989, 1990, 1993; MIOTO, 1990; MACEDO et 
MARQUES NETO, R. Evolução de caverna em quartzito e processos ...

al. 1991; SANTOS, 1999; HIRUMA et al. 2001; MARQUES NETO \& VIADANA, 2006), influenciou, juntamente com as mudanças climáticas do Quaternário, a evolução da caverna aqui apresentada. O rebaixamento do nível de base, que é conseqüência do soerguimento, favoreceu a incisão e a formação de uma cachoeira e de uma garganta na base da galeria, colocando em tela o falhamento por onde escoa a água pela referida queda, que tende a desaparecer por erosão regressiva. A mudança no nível de base vem instigando uma reativação generalizada de cabeceiras que vem evoluindo por intermédio da dissolução, pontuando, conforme foi exposto, uma série de pequenas depressões fechadas que rodeiam a Gruta do Sobradinho. O estudo de processos cársticos em São Thomé das Letras foi demonstrativo da atuação do componente climático em consonância com a tectônica na evolução quaternária da paisagem. Ao mesmo tempo em que as formas observadas se mostraram resultantes de diferentes mecanismos de evolução, instalados conforme o imperativo climático vigente, também foi possível perceber a forma efetiva com que os esforços neotectônicos interferem na dinâmica da paisagem.

A complexidade inerente aos processos de evolução do modelado cárstico, regida pela atuação conjunta de agentes exógenos e endógenos, deve ficar registrada, ressaltando sua importância no entendimento da evolução integrada da paisagem.

Entre as manifestações cársticas observadas, a Gruta do Sobradinho é aquela que apresenta maior desenvolvimento, sendo que a proposta de evolução apresentada guarda consonância com os sistemas gerais de gênese e evolução de cavernas e cujos registros podem ser observados, em parte, através dos trabalhos de campo.

Fica registrada, a título de finalização, a importância do estudo das manifestações cársticas para o desenvolvimento da própria geomorfologia, pouco contemplada no Brasil por pesquisas ocupadas com esta temática, e também para a compreensão das formas de intemperismo químico que partilham dos imperativos morfogenéticos tropicais. 
MARQUES NETO, R. Evolução de caverna em quartzito e processos ...

\section{Referências bibliográficas}

ASMUS, H. E.; FERRARI, A. L. Hipótese sobre a causa do tectonismo cenozóico na região Sudeste do Brasil. IN: PETROBRÁS. Aspectos da margem continental leste e sudeste do Brasil. Rio de Janeiro, 1978.

AULER, A.; ZOGBI, L. Espeleologia: noções básicas. São Paulo: Redespeleo Brasil, 2005. 103p.

BIGARELLA, J. J. Estrutura e Origem das Paisagens Tropicais e Subtropicais (vol. 3). Florianópolis: ed. da UFSC, 1994.

HIRUMA, S. T.; RICCOMINI, C.; MODENESI-GAUTTIERI, M. C. Neotectônica no Planalto de Campos do Jordão. Revista Brasileira de Geociências. São Paulo, v. 31, n. 3, p. 375-384, 2001.

KING, L. C. A Geomorfologia do Brasil Oriental. Revista Brasileira de Geografia. Rio de Janeiro, 18: 147-265, 1956.

KOHLER, H. C. Geomorfologia Cárstica. In: GUERRA, A. J. T. \& CUNHA, S. B. Geomorfologia e Meio Ambiente. Rio de Janeiro: Bertrand do Brasil, 1995.

LINO, C. F.; ALLIEVI, J. Cavernas Brasileiras. São Paulo: Melhoramentos, 1980.

MACEDO, J. M.; BACOCCOLI, G.; GAMBOA, L. A. P. O tectonismo meso-cenozóico na região Sudeste. In: $2^{\circ}$ SIMPÓSIO DE GEOLOGIA DO SUDESTE. SBG/SP-RJ. Sao Paulo, 1991.

MARQUES NETO, R. \& VIADANA, A. G. Morfotectônica na bacia do Ribeirão Vermelho (São Thomé das Letras-MG): avanços nos estudos neotectônicos no setor meridional do Estado de Minas Gerais. Estudos Geográficos, Rio Claro, v. 4, n. 1, p. 67-77, 2006.

BRASIL, Ministério das Minas e Energia. Projeto RADAMBRASIL. Folha SF-23 Vitória/Rio de Janeiro. Rio de Janeiro, 1983. 
MARQUES NETO, R. Evolução de caverna em quartzito e processos ...

PACIULlO, F. V. P.; RIBEIRO, A.; ANDREIS, R. R. Reconstrução de uma Bacia Fragmentada: o Caso do Ciclo Deposicional Andrelândia. IN: II SIMPÓSIO SOBRE O CRÁTON DO SÃO FRANCISCO. Salvador, p. 224-226, 1993.

PILÓ, L. B. Geomorfologia Cárstica. Revista Brasileira de Geomorfologia. v.1, n. 1., 2000.

SAADI, A. Importância da neotectônica na morfogênese do leste e sul de Minas Gerais. In: Congresso ABEQUA, 2. (Anais). Rio de Janeiro, 1989.

Um "rift" neo-cenozóico na região de São João Del Rei - MG; Borda Sul do Cráton do São Francisco. In: $1^{\circ}$ WORKSHOP SOBRE NEOTECTÔNICA E SEDIMENTAÇÃO CENOZÓICA CONTINENTAL NO SUDESTE BRASILEIRO, 1990, Belo Horizonte. Boletim da Sociedade Brasileira de Geologia. Belo Horizonte: SGB, p. 63-79, 1990.

Neotectônica da Plataforma Brasileira: esboço e interpretações preliminares. Geonomos, v. 1, n. 1, p. 1-15, 1993.

SAADI, A.; NOCE, C. M.; QUINTÃO, N. H. Neotectônica na região sul de Minas Gerais: primeiras hipóteses. In: $5^{\circ}$ SIMPÓSIO DE GEOLOGIA, Minas Gerais. Anais do $5^{\circ}$ Simpósio de Geologia. Minas gerais: Núcleo Minas Gerais, p. 115-118, 1989.

SANTOS, M. DOS. Serra da Mantiqueira e Planalto do Alto Rio Grande: a bacia terciária de Aiuruoca e evolução morfotectônica. Rio Claro, 1999. 134p. Tese (Doutorado em Geociências) - Instituto de Geociências e Ciências Exatas, Universidade Estadual Paulista.

SILVA, S. M. Carstificação em rochas siliciclásticas: estudo de caso na Serra do Ibitipoca, Minas Gerais. 2004. 142p. Dissertação de Mestrado. Instituto de Geociências, Universidade Federal de Minas Gerais.

UAGODA, R.; AVELAR, A. S. COELHO NETTO, A. L. Contribuição a geoorfologia cárstica em rochas quartzíticas: médio 
MARQUES NETO, R. Evolução de caverna em quartzito e processos ...

vale do Rio Preto, RJ/MG. In: VI SIMPÓSIO NACIONAL DE GEOMORFOLOGIA，2006, Goiânia. Anais do VI Simpósio Nacional de Geomorfologia, Goiânia.

WERNIK, E.; PASTORE, E. L.; PIRES NETO, A. Cavernas em Arenito. Notícia Geomorfológica. Campinas, n. 13, v. 26. p. 5567, 1973.

WILLEMS, L.; POUCLET, A.; LENOIR, F.; VICAT, J. P. Phénomènes karstiques en milieux non-carbonatés. Zeitschrift für Geomorphologie. Berlin; Stuttgart, vol. 103, p. 193-214, 1996.

Recebido em fevereiro de 2007 Aceito em julho de 2007 
MARQUES NETO, R. Evolução de caverna em quartzito e processos ... 